\title{
Sofosbuvir and Daclatasvir Bypassing Genotypic Investigation of Chronic Hepatitis C Infection: A Real-Life Experience at Tertiary care center in North Indian Population Sofosbuvir and Daclatasvir Bypassing Genotypic Investigation
}

\author{
Amar Deep ${ }^{1}$, Ajay Kumar², Sumit Rungta ${ }^{3}$ and Suchit Swaroop ${ }^{1}$ \\ 'Experimental and Public Health Laboratory, Department of Zoology, University of Lucknow, Lucknow - 226007, \\ Uttar Pradesh, India; jsa.amardeep@gmail.com \\ 2Department of Medicine, King George's Medical University, Lucknow - 226003, Uttar Pradesh, India; \\ drajaymd12345@gmail.com \\ ${ }^{3}$ Department of Medical Gastroenterology, King George's Medical University, Lucknow - 226003, \\ Uttar Pradesh, India; drsumitrungta79@gmail.com, drsswaroop@gmail.com
}

\begin{abstract}
Background and Aims: The goal of Hepatitis C Virus infection treatment is to remove the virus, to avoid advancement of Hepatitis C Virus (HCV) infection and progression of related disease such as liver cirrhosis and hepatocellular carcinoma and to achieve End of Treatment Response (ETR) with 12-week therapy and Sustained Virological Response (SVR) at post-treatment week 12 (SVR-12), which is defined as undetectable HCV RNA at 12 weeks post ETR. In the Compassionate Use Program (CUP) in Europe, Sofosbuvir (SOF) and Daclatasvir (DCV) were used in all genotypes and achieved SVR-12. Aims: Our aim is to compare the efficacy and effectiveness of Sofosbuvir and Daclatasvir in the treatment of HCV infection in the patients who could not afford for the investigating of HCVGenotype and to those in whom genotyping was done. Methods: Group 1 includes ten patients, given Sofosbuvir and Daclatasvir without genotype and group 2 includes nine patients, given Sofosbuvir and Daclatasvir with genotype. The patient group selection was done using a randomized table generated by using excel. All the patients in the groups completed the twelve weeks treatment with twelve weeks and twenty-four weeks of follow up. All the nineteen patients were given Sofosbuvir and Daclatasvir for twelve weeks and the endpoint of therapy was marked by undetectable HCV-RNA in blood by ETR-12 (end of treatment response), Sustained Virological Response at post-treatment week 12 (SVR-12) and Sustained Virological Response at post-treatment week 24 (SVR24). Results: Quantitative HCV-RNA (IU/ml) by RT-PCR was undetectable in all the patients in both groups at the end of treatment (ETR-12) and SVR-12- and SVR-24-weeks follow-up after completion of treatment i.e. Sofosbuvir and Daclatasvir has 100\% ETR-12, SVR-12 and SVR-24 in both the groups. Conclusion: If patients do not investigate for genotype and use the Sofosbuvir and Daclatasvir in HCV infected patients, there is no effect on outcome ETR. This will reduce the risk of late stage complications such as liver cirrhosis and hepatocellular carcinoma and will also leads to the economic benefits such as no extra burden on patients.
\end{abstract}

Keywords: Cirrhosis, End of Treatment Response (ETR), Hepatocellular Carcinoma (HCC), Sofosbuvir and Daclatasvir (SOF+DCV), Steatosis, Sustained Virological Response (SVR)

\section{Background}

Hepatitis C Virus (HCV) is a positive-strand RNA virus of the Flaviviridae family and contains a single-stranded RNA genome of approximate 9600 nucleotides and is a globally prevalent pathogen and also a major cause of healthcare burden in India. HCV infection is a significant problem in India. HCV has six major genotype 1 to 6 , genotype 1 is the most prevalent genotype globally (46\%), followed by genotype 3 in $22 \%$ and genotype 2 and 4 in 13\% each and there is a significant genotypic variation across various geographic regions globally. While genotype 1 predominates in Europe, North America and Australia, genotype 3 is more prevalent in Asian countries such as India, Pakistan and Bangladesh. HCV is the disease that has affected around 200 million people globally ${ }^{1}$. End-stage Liver Disease (ESLD) due to chronic hepatitis C infection remains

*Author for correspondence 
the leading cause for liver transplantation, placing a major burden on health care services ${ }^{2,3}$. Although, the impact of HCV heterogeneity and genotypes on the clinical management of chronic HCV infection has not been established and its role as an epidemiologic marker has been clearly shown. The sensitiveness of serologic and virologic assays for the detection of HCV may be influenced by the heterogeneity of HCV. However, the accurate role of genotypes in the progression of liver disease, the outcome of HCV infection, and the response to the antiviral therapy are much less well understood than their role as an epidemiologic marker. In India the most prevalent genotype is 3 with subtype $3 a$ and $3 b^{4,5}$. In the Indian scenario, due to the absence of a HCV surveillance system in India, there is a lack of knowledge about the actual number of people living with HCV-related liver diseases and the people who died because of it. The calculated prevalence of HCV infection in India is about $1-1.9 \%{ }^{6}$ although variations have been reported in literature across various geographical regions in India. The disease is most prevalent in Punjab, Haryana, Andhra Pradesh, Puducherry, Arunachal Pradesh and Mizoram. An official statement is released by the Delhi-based Institute, Institute of Liver and Biliary Science (ILBS) in 2014, highlighted the number of people living with chronic Hepatitis C infection, which was approximately 12 million. HCV infection is just one part of the complete burden of viral hepatitis in India and is the blood-borne and can be transmitted from one human to another? . Oral combinations of Direct-acting Antivirals (DAAs) have become the standard of care for the treatment of chronic HCV infection ${ }^{8-11}$. In clinical trials, the rates of sustained virological response at post-treatment week 12 (SVR12) exceeding 90\% have been reported for several drug combinations, with safety profiles superior to those of peg interferon-based regimens. Daclatasvir (DCV) is a potent, pan-genotypic inhibitor of the HCV NS5A protein; Sofosbuvir (SOF) is a pan-genotypic nucleotide analogue inhibitor of the HCV NS5B RNA polymerase ${ }^{12,13}$. In the phase III drug trial studies, the 12-week, once-daily oral combination of DCV and $\mathrm{SOF}$, with or without ribavirin $(\mathrm{DCV}+\mathrm{SOF} \pm \mathrm{RBV})$, was well tolerated and achieved SVR12 rates exceeding $90 \%$ in patients who have been challenging to treat effectively, including those with advanced cirrhosis, HIV/HCV co-infection, HCV genotype 3 infection and HCV recurrence after liver transplant ${ }^{14-16}$.

\section{Methods}

\subsection{Patients and Treatment}

It was an observational study conducted from February 2017 to December 2017 at the outpatients of Medical Gastroenterology unit of medicine department. A favorable ethical opinion [Ref. no: 103/Ethics/R.Cell-17, Dated: 22/08/2017] was obtained from the King George's Medical University ethical committee [Registration no.: ECR/262/Inst/UP/2013/RR-16] for the study. A total of 19 patients with mean age of $38.6 \pm 8.4$ years, were enrolled after informed consent. HCV infection was confirmed by $3^{\text {rd }}$ generation ELISA and patients with chronic infection of HCV, confirmed with detectable HCV-RNA in $\mathrm{IU} / \mathrm{ml}$ (quantitative analysis) with a genotype 3 by RT-PCR, were included in the study. These patients were categorized into 2 groups. Group 1 includes 10 patients, given Sofosbuvir and Daclatasvir without genotype and group 2 include 9 patients, given Sofosbuvir and Daclatasvir with genotype 3. Those with the features of decompensated liver disease such as ascites, variceal bleeding or portosystemic encephalopathy and those with comorbid conditions such as positive hepatitis B surface antigen, positive HIV (Human Immunodeficiency Virus), other chronic liver diseases i.e., alcoholic liver disease, hepatotoxic drugs, autoimmune chronic hepatitis, treatment experienced patients and hemochromatosis were excluded from the study. Using Graph Pad Prism software package carried out all statistical analysis and unpaired student's t-test was employed to compare numerical variables between patients with or without genotype.

\subsection{Laboratory Methods}

HCV viral load was measured using real time PCR as per protocol described by ${ }^{17}$. HCV RNA positive samples were genotyped using core region, as described by ${ }^{18}$ with slight modifications. Real Time PCR with lower limit of detection of $20 \mathrm{IU} / \mathrm{mL}$. Absence of detectable HCV RNA using this assay at different time points was used to define ETR, SVR-12 and SVR-24.

\section{Results}

A total nineteen patients consented to begin the therapy and the study will be categorized into two groups. Group 1 included ten patients, given Sofosbuvir and Daclatasvir without investigating genotype with the mean age group of $41.2 \pm 11.5$ and the group 2 included nine patients, given Sofosbuvir and Daclatasvir with genotype 3, with the mean age group of $38.6 \pm 8.44$ years are summarized in table 1 and table $2^{19}$. All the patients completed the 12 weeks treatment (ETR 12), 12 weeks follow up SVR-12 and SVR-24. HCV RNA was undetectable in all the patients in both groups at the ETR andSVR-12 (100\% ETR-12 and SVR-12 and SVR-24 achieved in both the groups).

\subsection{Follow-up (ETR-12 and SVR-12)}

All patients underwent quantitative analysis of HCV-RNA at the end of treatment response (12 weeks i.e. ETR-12) and 
Characteristics and outcomes of patient's baseline and follow-up characteristic are summarized as bellow:

Table 1. Comparison of baseline and follow-up treatment characteristic of group-1 (Without GT) patients ${ }^{19}$

\begin{tabular}{|l|l|l|l|l|l|l|}
\hline Without GT (Group-1) \\
\hline $\begin{array}{l}\text { Treatment } \\
\text { SOF + DCV }\end{array}$ & Baseline & & \multicolumn{3}{l|}{ Follow-up Treatment } & \multicolumn{2}{l|}{ Unpaired t test } \\
\hline $\begin{array}{l}\text { Baseline } \\
\text { Characteristic }\end{array}$ & Mean & SD & Mean & SD & P value & $\begin{array}{l}\text { P value } \\
\text { summary }\end{array}$ \\
\hline Hb & 13.3 & 2.1 & 13.7 & 1.8 & 0.6708 & ns \\
\hline PLT & 192000 & 41923.21 & 215200 & 33522.1 & 0.1885 & ns \\
\hline Alb & 4.8 & 0.6 & 4.8 & 0.7 & 0.8864 & ns \\
\hline AST & 74.6 & 63.4 & 34.5 & 8.5 & 0.0628 & ns \\
\hline ALT & 82.8 & 65.6 & 39.8 & 9.1 & 0.0549 & ns \\
\hline PT & 13.6 & 0.7 & 14.2 & 0.4 & 0.0361 & $*$ \\
\hline
\end{tabular}

$P$ value less than 0.05 considered as significant.

Table 2. Comparison of baseline and follow-up treatment characteristic of group 2 (With GT-3) patients ${ }^{19}$

\begin{tabular}{|c|c|c|c|c|c|c|}
\hline \multicolumn{7}{|c|}{ With GT 3 (Group-2) } \\
\hline \multirow{2}{*}{$\begin{array}{l}\text { Treatment SOF } \\
+ \text { DCV } \\
\text { Baseline } \\
\text { Characteristic } \\
\end{array}$} & \multirow{2}{*}{$\begin{array}{l}\text { Baseline } \\
\text { Mean }\end{array}$} & \multirow[b]{2}{*}{ SD } & \multicolumn{2}{|c|}{ Follow-up Treatment } & \multicolumn{2}{|c|}{ Unpaired $t$ test } \\
\hline & & & Mean & SD & $P$ value & $\begin{array}{l}\text { P value } \\
\text { summary }\end{array}$ \\
\hline $\mathrm{Hb}$ & 11.6 & 1.8 & 12.1 & 2.0 & 0.5599 & ns \\
\hline PLT & 190889 & 70029.4 & 222889 & 42345.1 & 0.2579 & ns \\
\hline Alb & 4.0 & 0.5 & 4.0 & 0.4 & 0.8716 & ns \\
\hline AST & 102.6 & 69.4 & 37.2 & 17.7 & 0.0146 & * \\
\hline ALT & 97.3 & 93.2 & 37.4 & 13.6 & 0.0744 & ns \\
\hline PT & 14.1 & 1.4 & 14.6 & 0.5 & 0.3755 & ns \\
\hline
\end{tabular}

$P$ value less than 0.05 considered as significant.

12 weeks after stopping the treatment (SVR-12). The ETR and SVR were determined for each patient with quantitative HCVRNA of lower limit of detection as $20 \mathrm{IU} / \mathrm{ml}$. ETR was defined as negative quantitative HCV-RNA at the end of treatment, while SVR was defined as negative quantitative HCV-RNA 12 weeks after the completion of therapy and all the patients achieved 100\% ETR-12 and SVR-12 in both the enrolled groups. The outcomes of ETR-12 and SVR-12 of patients on Sofosbuvir and Daclatasvir combination therapy of both groups are summarized as below in (Table 3 and Table 4). All the patients achieved $100 \%$ ETR-12 and SVR-12 respectively.

\subsection{Follow-up (SVR-24)}

In group 1 (i.e. without $\mathrm{GT}, \mathrm{n}=10$ ), total follow up patients were 7 and 3 patients were lost to follow up and all the follow up seven patients, underwent quantitative analysis of $\mathrm{HCV}$ -
Table 3. HCV-RNA at baseline, ETR-12 and SVR-12 without genotype $\mathrm{e}^{19}$

\begin{tabular}{|l|l|l|l|}
\hline $\begin{array}{l}\text { Treatment Regimen } \\
\text { Without GT (Group 1) }\end{array}$ & $\begin{array}{l}\text { HCV-RNA at } \\
\text { Baseline }\end{array}$ & ETR-12 & SVR-12 \\
\hline SOF + DCV & 10000 & 0 & 0 \\
\hline SOF + DCV & 7300000 & 0 & 0 \\
\hline SOF + DCV & 490000 & 0 & 0 \\
\hline SOF + DCV & 110000 & 0 & 0 \\
\hline SOF + DCV & 10000 & 0 & 0 \\
\hline SOF + DCV & 10000 & 0 & 0 \\
\hline SOF + DCV & 94000 & 0 & 0 \\
\hline SOF + DCV & 60100 & 0 & 0 \\
\hline SOF + DCV & 1093 & 0 & 0 \\
\hline SOF + DCV & 15000 & 0 & 0 \\
\hline
\end{tabular}

Sofosbuvir and Daclatasvir 
Table 4. HCV-RNA at baseline, ETR-12 and SVR-12 with genotype $^{19}$

\begin{tabular}{|l|l|l|l|}
\hline $\begin{array}{l}\text { Treatment Regimen } \\
\text { With GT (Group 2) }\end{array}$ & HCV-RNA & ETR-12 & SVR-12 \\
\hline SOF + DCV & 6900000 & 0 & 0 \\
\hline SOF + DCV & 93000 & 0 & 0 \\
\hline SOF + DCV & 110000 & 0 & 0 \\
\hline SOF + DCV & 9800000 & 0 & 0 \\
\hline SOF + DCV & 160000 & 0 & 0 \\
\hline SOF + DCV & 1400000 & 0 & 0 \\
\hline SOF + DCV & 130000 & 0 & 0 \\
\hline SOF + DCV & 17000000 & 0 & 0 \\
\hline SOF + DCV & 3700000 & 0 & 0 \\
\hline
\end{tabular}

Sofosbuvir and Daclatasvir

RNA at SVR-24 after stopping the treatment and found with a quantitative HCV-RNA of lower than detection limit (20 IU/ $\mathrm{ml}$ ). In group 2 (i.e. with $\mathrm{GT}, \mathrm{n}=9$ ), total follow up patients were 8 and 1 patients were lost to follow up and all the follow up eight patients, underwent quantitative analysis of HCVRNA at SVR-24 after stopping the treatment found lower than detection limit $(20 \mathrm{IU} / \mathrm{ml})$.

\section{Discussion}

We reported here our experience with DAA-based regimens for the treatment of CHC-3 infection. Hepatitis C Virus with genotype 3 has generally proven to be more challenging to treat with oral antivirals than other genotypes. This present study involved a small real-world cohort of patients with genotype 3 infection chronic liver disease provides data on the clinical effectiveness of Sofosbuvir and Daclatasvir in a challenging subset of patients with very limited treatment options. The result of this study suggests that overall ETR-12 and SVR-12 rates of $100 \%$ with and without investigating HCV Genotype. In a European CUP provided clinically relevant information on the effectiveness and safety of Sofosbuvir and Daclatasvir, with or without RBV, in a large cohort of patients with advanced liver disease and resulted in an overall SVR12 rate of $91 \%{ }^{20}$. Similar study demonstrated that high SVR12 rates were observed in patient subgroups with characteristics regarded as more difficult to cure, such as decompensated cirrhosis and genotype 3 infections with cirrhosis ${ }^{20}$.

\section{Conclusion}

If patients do not investigate for genotype and use the Sofosbuvir and Daclatasvir in HCV infected patients, there is no effect on the outcome end of treatment response. Sofosbuvir and Daclatasvir have shown to be very effective and successful treatment of the Hepatitis C Virus infection with achievement of virological response and have no resistance in HCV genotype 3 treatments in our study population. The promising results of our study will aid in better outcomes and therefore help in eradication of the Hepatitis C Virus.

\section{Abbreviations}

OPD: Out Patients Department, HCV: Hepatitis C Virus, HCC: Hepatocellular Carcinoma, BMI: Body Mass Index, Hb: Hemoglobin, AST: Aspartate Aminotransferase, ALT: Alanine Aminotransferase, ALP: Alkaline Phosphatase, PT: Prothrombin Time, Anti HCV: Hepatitis C Antibody, RNA Level: Ribo-nucleic Acid Level, HIV: Human Immunodeficiency Virus, HCV-Genotype: Hepatitis C Virus Genotype, ELISA: Enzyme-linked Immune Sorbent Assay.

\section{Reference}

1. Nazish B, Tariq M. An overview about Hepatitis C: A devastating virus. Crit Rev Microbiol. 2010; 36(2):91-133. PMid: 20345213. https://doi.org/10.3109/10408410903357455

2. Alter MJ, Margolis HS, Krawczynski K, Judson FN, Mares A, Alexander WJ, et al. The natural history of communityacquired Hepatitis $C$ in the United States. The Sentinel Counties Chronic non-A, non-B Hepatitis Study Team. N Engl J Med. 1992; 327:1899-905. PMid: 1280771. https://doi.org/10.1056/ NEJM199212313272702

3. Kim WR. The burden of Hepatitis Cin the United States. Hepatology. 2002; 36:S30-4. https://doi.org/10.1002/hep.1840360705

4. Singh S, Malhotra V, Sarin SK. Distribution of Hepatitis C Virus genotypes in patients with chronic Hepatitis $\mathrm{C}$ infection in India. Indian J Med Res. 2004 Apr; 119:145-8.

5. Prakash S, Jain A, Jain B. Development of novel triplex singlestep real-time PCR assay for detection of Hepatitis Virus B and C simultaneously. Virol. 2016 May; 492:101-7. PMid: 26914508. https://doi.org/10.1016/j.virol.2016.01.029

6. Sievert W, Altraif I, Razavi HA, Abdo A, Ahmed EA, Alomair A, et al. A systematic review of Hepatitis C Virus epidemiology in Asia, Australia and Egypt. Liver Int. 2011; 31(sup 2):61-80. PMid: 21651703. https://doi.org/10.1111/j.1478-3231.2011.02540.x

7. http://www.millenniumpost.in/india-lacks-accurate-data-totackle-hepatitis-155867

8. American Association for the Study of Liver Diseases and the Infectious Diseases Society of America. Recommendations for testing, managing and treating hepatitis C. 2015. http://www. Hcvguidelines.org/full-Report-View

9. European Association for Study of Liver. EASL Recommendations on Treatment of Hepatitis C 2015. J Hepatol. 2015; 63:199-236. PMid: 25911336. https://doi.org/10.1016/j.jhep.2015.03.025

10. Majumdar A, Kitson MT, Roberts SK. Systematic review: Current concepts and challenges for the direct-acting antiviral era in 
Hepatitis C Cirrhosis. Aliment Pharmacol Ther. 2016; 43:127692. PMid: 27087015. https://doi.org/10.1111/apt.13633

11. Holmes JA, Thompson AJ. Interferon-free combination therapies for the treatment of Hepatitis C: Current insights. Hepat Med. 2015; 7:51-70. PMid: 26586968 PMCid: PMC4636173. https:// doi.org/10.2147/HMER.S55864

12. Gao M. Antiviral activity and resistance of HCV NS5A replication complex inhibitors. Curr Opin Virol. 2013; 3:514-20. PMid: 23896281. https://doi.org/10.1016/j.coviro.2013.06.014

13. Sofia MJ, Bao D, Chang W, Du J, Nagarathnam D, Rachakonda $S$, et al. Discovery of a $\beta$-d-20-deoxy-20- $\alpha$-fluoro-20- $\beta$ Cmethyluridine nucleotide prodrug (PSI-7977) for the treatment of Hepatitis C Virus. J Med Chem. 2010; 53:7202-18. PMid: 20845908. https://doi.org/10.1021/jm100863x

14. Wyles DL, Ruane PJ, Sulkowski MS, et al. Daclatasvir plus Sofosbuvir for HCV inpatients coinfected with HIV-1. N Engl J Med. 2015; 373:714-25.

15. Nelson DR, Cooper JN, Lalezari JP, Lawitz E, Pockros PJ, Gitlin N, et al. All-oral 12-week treatment with Daclatasvir plus Sofosbuvir in patients with Hepatitis C Virus genotype 3 infection: ALLY-3 phase III study. Hepatology. 2015; 61:1127-35. PMid: 25614962 PMCid: PMC4409820. https://doi.org/10.1002/hep.27726

16. Poordad F, Schiff ER, Vierling JM, Landis C, Fontana RJ, Yang R, et al. Daclatasvir with Sofosbuvir and ribavirin for Hepatitis C Virus infection with advanced cirrhosis or post-liver transplant recurrence. Hepatology. 2016; 63:1493-505. PMid: 26754432 PMCid: PMC5069651. https://doi.org/10.1002/hep.28446

17. Prakash S, Shukla S, Ramakrishna V, Jain A. Distribution of Hepatitis C genotypes in Uttar Pradesh, India; Rare genotype 4 detected. Journal of Medical Virology. 2018; 90:1875-81. PMid: 30085356. https://doi.org/10.1002/jmv.25277

18. Lole KS, Jha JA, Shrotri1 SP, Tandon BN, Mohan Prasad VG, Vidya A. Arankalle VA. Comparison of Hepatitis C Virus genotyping by $5^{\prime}$ Noncoding Region- and Core-based reverse transcriptase PCR assay with sequencing and use of the assay for determining subtype distribution in India. J Clin Microbiol. 2003 Nov; 41(11):5240-4. PMid: 14605173 PMCid: PMC262521. https://doi.org/10.1128/JCM.41.11.5240-5244.2003

19. Deep A, Kumar A, Swaroop S. There is no need of investigating for genotype if we use Sofosbuvir and Daclatasvir for chronic Hepatitis C infection. Journal of Clinical and Experimental Hepatology. 2017; 7(2):S19. https://doi.org/10.1016/j.jceh.2017. 05.043

20. Welzel TM, Petersen J, Herzer K, Ferenci P, Gschwantler M, Wedemeyer H, et al. Daclatasvir plus Sofosbuvir, with or without ribavirin, achieved high sustained virological response rates in patients with $\mathrm{HCV}$ infection and advanced liver disease in a realworld cohort. Gut. 2016; 65:1861-70. PMid: 27605539 PMCid: PMC5099229. https://doi.org/10.1136/gutjnl-2016-312444 